\title{
Study on Performance Evaluation of Small Axial Fan
}

\author{
Toshiyuki Hirano1, Kazuma Takahashi², Gaku Minorikawa3 ${ }^{3}$ \\ ${ }^{1}$ Mechanical Engineering Course, Department of Science and Engineering, Kokushikan University, Tokyo, Japan \\ ${ }^{2}$ Gnippon Keiki Works, Ltd, Ibaraki, Japan \\ ${ }^{3}$ Department of Mechanical Engineering, Faculty of Science and Engineering, Hosei University, Tokyo, Japan \\ Email: thirano@kokushikan.ac.jp
}

How to cite this paper: Hirano, T., Takahashi, K. and Minorikawa, G. (2017) Study on Performance Evaluation of Small Axial Fan. Open Journal of Fluid Dynamics, 7, 546-556.

https://doi.org/10.4236/ojfd.2017.74037

Received: October 24, 2017

Accepted: December 11, 2017

Published: December 14, 2017

Copyright (c) 2017 by authors and Scientific Research Publishing Inc. This work is licensed under the Creative Commons Attribution International License (CC BY 4.0).

http://creativecommons.org/licenses/by/4.0/

\begin{abstract}
In order to establish the design methodology of a small axial fan, the axial fan with impeller diameter of $36 \mathrm{~mm}$ was designed, manufactured and tested. Especially, in order to investigate the influence of difference in blade cord length and blade thickness on performance characteristics, the performance characteristics obtained by the designed axial fans with difference blade shapes were examined. Also, by using CFD, the same flow field as the experiment was visualized. It was found that the lift of the blade was increased and the performance was improved in high flow rate region by thinning of the blade thickness and by extending the blade chord length.
\end{abstract}

\section{Keywords}

Axial Fan, Performance, CFD

\section{Introduction}

In recent years, IT equipment such as personal computer, multi-function printer, audio and visual equipment and so on has been widely used because of the development of information and communication technologies. Since the demand for downsizing and improvement of the processing speed is increasing, the packaging density of the devices is getting higher and the thermal design is getting severer. So, the forced air cooling by small axial fan is commonly used in the thermal design. However, the efficiency of small axial fan is extremely low due to the restriction of the production such as cost and manufacturing, compared with industrial fans. Thus, there are few reports about the design and performance prediction on small fan (e.g. Ito, et al. [1], Iwase, et al. [2] [3] [4], Sasajima and Kawaguchi [5]). In this study, in order to establish the design metho- 
dology of a small axial fan, the axial fan with impeller diameter of $36 \mathrm{~mm}$ was designed, manufactured and tested. Especially, in order to investigate the influence of difference in blade cord length and blade thickness on performance characteristics, the performance characteristics obtained by the designed axial fans with difference blade shapes were examined. Also, by using CFD, the same flow field as the experiment was visualized.

\section{Design of Fan}

The small axial fan used in this study is shown in Figure 1. Axial fan with the frame size of $40 \mathrm{~mm}$ to be loaded into a car navigation system at present was adopted as a subject of small axial fan in this study. The casing consists of frame and spoke which supports a motor, and the spoke is installed behind the impeller. The motor which drives small axial fan is inside the boss of an impeller, and a rotor is installed outside the motor. It's the feature that the inside diameter is large relatively to the outside diameter of the impeller for this type of fan. Impeller has the outlet diameter of $36 \mathrm{~mm}$, and inner diameter of $23 \mathrm{~mm}$ and height of $6.2 \mathrm{~mm}$. Table 1 and Figure 2 show the main specification of the airfoil shape designed by this study and the sectional view of airfoil, respectively.

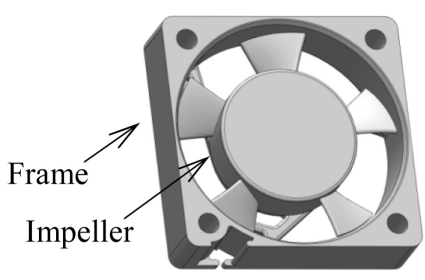

(a)

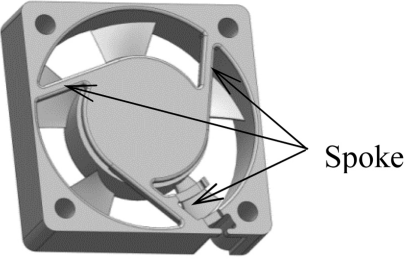

(b)

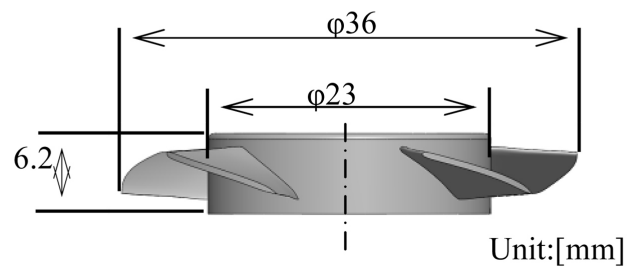

(c)

Figure 1. Small axial fan used by this study. (a) Inlet side. (b) Outlet side. (c) Experimental apparatus.

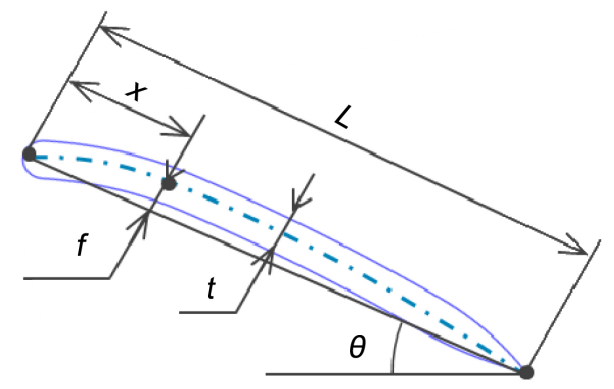

Figure 2. Cross-sectional view of airfoil shape. 
Table 1. Specification of airfoil shape.

\begin{tabular}{|c|c|c|c|c|}
\hline & \multirow{2}{*}{ Symbol } & \multirow{2}{*}{ Unit } & \multicolumn{2}{|c|}{ Specification } \\
\hline & & & Tip & Hub \\
\hline Airfoil section & - & - & \multicolumn{2}{|c|}{ Cambered Plate } \\
\hline Maximum camber & $f$ & [\%] & \multicolumn{2}{|c|}{6} \\
\hline Maximum camber location & $x$ & [\%] & \multicolumn{2}{|c|}{30} \\
\hline Number of blades & $Z$ & & \multicolumn{2}{|c|}{5} \\
\hline Blade thickness & $t$ & {$[\mathrm{~mm}]$} & \multicolumn{2}{|c|}{0.5} \\
\hline Chord length & $L$ & {$[\mathrm{~mm}]$} & 11.6 & 7.2 \\
\hline Setting angle & $\theta$ & [deg.] & 14.5 & 36 \\
\hline
\end{tabular}

Cambered Plate with the fixed blade thickness was used for the blade cross-sectional shape in consideration of productivity. The camber and its location were designed to obtain enough lift. The blade number of the impeller is 5 , and the thickness is $0.5 \mathrm{~mm}$. The chord length of hub side is $7.2 \mathrm{~mm}$ and that of tip ide is $11.6 \mathrm{~mm}$. Airfoil shape was defined at multiple blade cross-sections between the Tip side and the Hub side, and a chord length and the setting angle of the blade were established at the respective sections. The impellers with the different shape of blade were designed to investigate the influence of the difference in the chord length and blade thickness on the performance.

Table 2 shows the specification of the shape of blade which was changed the parameter of a chord length and blade thickness, and Figure 3 shows the axial impeller models which were changed the shape. A chord length of hub side was fixed and that of tip side was changed based on the length of the standard fan. Moreover, the blade thickness was changed from $0.3 \mathrm{~mm}$ to $1.0 \mathrm{~mm}$ for designed impellers with chord length of $19.5 \mathrm{~mm}$ in this study. In the following, each impeller was named as shown in Table 2.

\section{Experimental Apparatus and Method}

The experimental apparatus is shown in Figure 4. This is so called a double chamber PQ (fan air volume $(Q)$-static pressure $(P)$ ) tester according to the Japanese industrial standard (JIS B 8330) and AMCA STANDARD210 (AMCA: Air Movement and Control Association). This apparatus mainly consists of a tested fan, two chambers, an orifice and an auxiliary blower. The wall static pressure holes were installed at $40 \mathrm{~mm}$ upstream and downstream of the orifice. The tested fans were manufactured using a stereo lithography machine (Envision TEC, ULTRA). The impeller was installed in a casing with DC blushless motor (NIPPON KEIKI WORKS, LF40A12). The inner diameter of the casing is $38 \mathrm{~mm}$ and the clearance between the bladetip and the casing was $1 \mathrm{~mm}$. The static pressure $p_{s}$, which was the wall pressure on the front chamber, was measured by a small digital differential pressure gauge (NAGANO KEIKI, GC31). The flow rate $Q$ was obtained by measuring the differential pressure before and behind the orifice, which was defined by the following equations: 
Table 2. Specification of tested fan.

\begin{tabular}{|c|c|c|c|}
\hline \multirow{2}{*}{ Tested fan } & \multirow{2}{*}{$\begin{array}{l}\text { Blade thickness } t \\
{[\mathrm{~mm}]}\end{array}$} & \multicolumn{2}{|c|}{ Chord length $L[\mathrm{~mm}]$} \\
\hline & & Tip & Hub \\
\hline TYPE 3180 & 0.3 & $19.5(180 \%)$ & \\
\hline TYPE 4100 & & $11.6(100 \%)$ & \\
\hline TYPE 4120 & & $14.0(120 \%)$ & \\
\hline TYPE 4140 & 0.4 & $15.7(140 \%)$ & \\
\hline TYPE 4160 & & $17.6(160 \%)$ & \\
\hline TYPE 4180 & & $19.5(180 \%)$ & \\
\hline TYPE 5100 & & $11.6(100 \%)$ & \\
\hline TYPE 5120 & & $14.0(120 \%)$ & 7.2 \\
\hline TYPE 5140 & 0.5 & $15.7(140 \%)$ & \\
\hline TYPE 5160 & & $17.6(160 \%)$ & \\
\hline TYPE 5180 & & $19.5(180 \%)$ & \\
\hline TYPE 6180 & 0.6 & $19.5(180 \%)$ & \\
\hline TYPE 8180 & 0.8 & $19.5(180 \%)$ & \\
\hline TYPE 10180 & 1.0 & $19.5(180 \%)$ & \\
\hline
\end{tabular}

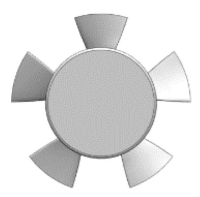

Tip chord length $=100 \%$

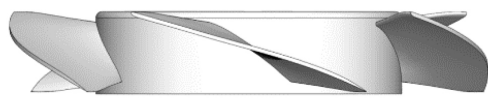

Blade thicknesst $=0.3 \mathrm{~mm}$

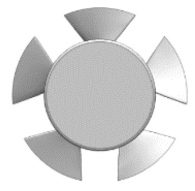

$140 \%$

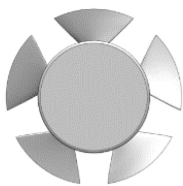

$160 \%$

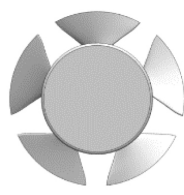

$180 \%$

(a)

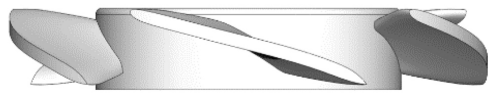

Blade thickness $t=1.0 \mathrm{~mm}$

(b)

Figure 3. Tested impeller. (a) Difference of chord length. (b) Difference of blade thickness.

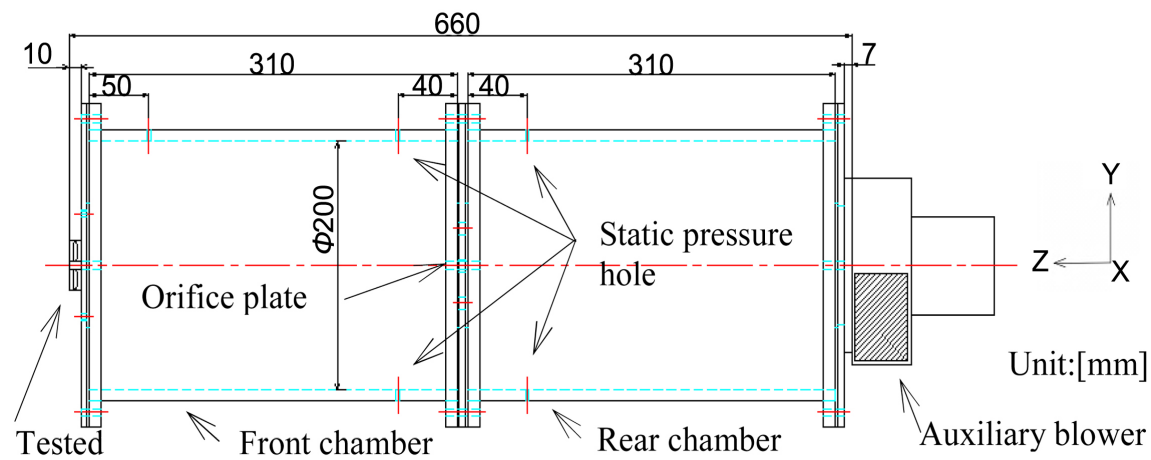

Figure 4. Experimental apparatus. 


$$
\begin{gathered}
Q=60 C A \sqrt{\frac{2 \Delta p}{\rho}} \\
\rho=\frac{P_{a}}{R T}
\end{gathered}
$$

$Q$ : Flow rate $\left[\mathrm{m}^{3} / \mathrm{min}\right], C$ : Coefficient of flow rate correction $[-], A$ : Area of orifice $\left[\mathrm{m}^{2}\right]$,

$\Delta p$ : Differential pressure $[\mathrm{Pa}], \rho$ : Fluid Density $\left[\mathrm{kg} / \mathrm{m}^{3}\right], P_{a}:$ Atmospheric pressure $[\mathrm{Pa}]$,

$R$ : Gas constant [J/(kg.K)], T: Temperature $[\mathrm{K}]$.

To obtain a performance characteristic curve which is called a PQ curve (fan air volume $(Q)$-static pressure $(P)$ characteristic diagram), firstly, the maximum static pressure $p_{\text {smax }}$ was measured by sealing the chamber and the maximum flow rate $Q_{\max }$ was obtained so as the pressure difference between the orifices was set to $0 \mathrm{~Pa}$ by adjusting the auxiliary blower. Then any combinations of $p_{s}$ and $Q$ were obtained by dividing $Q_{\max }$ to several points. The rotational speed of the impeller was kept at $6800 \mathrm{rpm}$ by adjusting the input voltage.

\section{CFD Analyses}

In this study, CFD (computational fluid dynamics) analysis of the same flow fields as the experiment was performed by using commercial software (Software Cradle, SCRYU/Tetra). The calculation grids were mainly non-structural tetra mesh and partially structural hexagonal mesh around the blade and the wall surface. The calculating region consists of inlet, outlet and fan as rotational region. The number of grids is about 5,800,000. The dimensions of the outlet region imitated the experimental apparatus. The entire and enlarged view of the calculation models are illustrated in Figure 5. As boundary conditions, the inlet

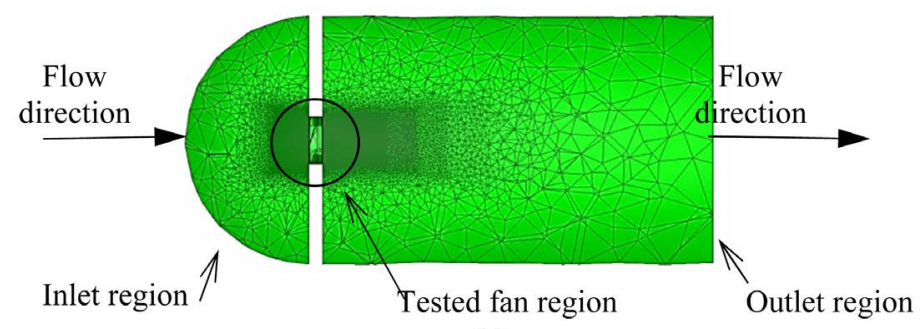

(a)

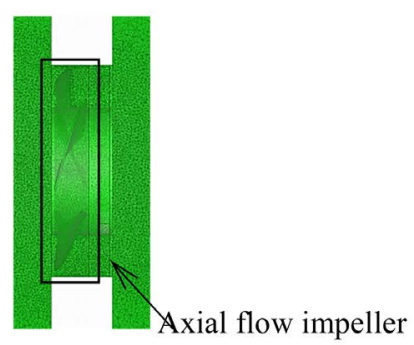

(b)

Figure 5. Calculation grid used for analysis. (a) Overall view of computational grids. (b) Enlarged view of tested fan region. 
surface was set as atmospheric pressure and the outlet surface was regulated by given flow rates. The tested fan region was constructed by moving meshes as ALE (Arbitrary Lagrangian and Eularian) method. To obtain the maximum flow rate, static pressure at the outlet surface was set to $0 \mathrm{~Pa}$. The calculation was performed by steady RANS (Reynolds Averaged Navier-Stokes) and the turbulent model was a standard $k-\varepsilon$ model. Although it is considered that a complicated vortex flow exists inside the fan used in this study, the tendency of the overall performance characteristic was investigated using $k-\varepsilon$ model which is generally used.

\section{Results and Discussion}

\subsection{Experimental Results}

Figure 6(a) and Figure 6(b) show the PQ curves of the tested fans which were blade thickness of $0.4 \mathrm{~mm}$ and $0.5 \mathrm{~mm}$ with different chord length. Figure $6(\mathrm{c})$ also shows those of the chord length of $19.5 \mathrm{~mm}$ at the tip side with different blade thickness. The vertical axis shows the static pressure, and the horizontal

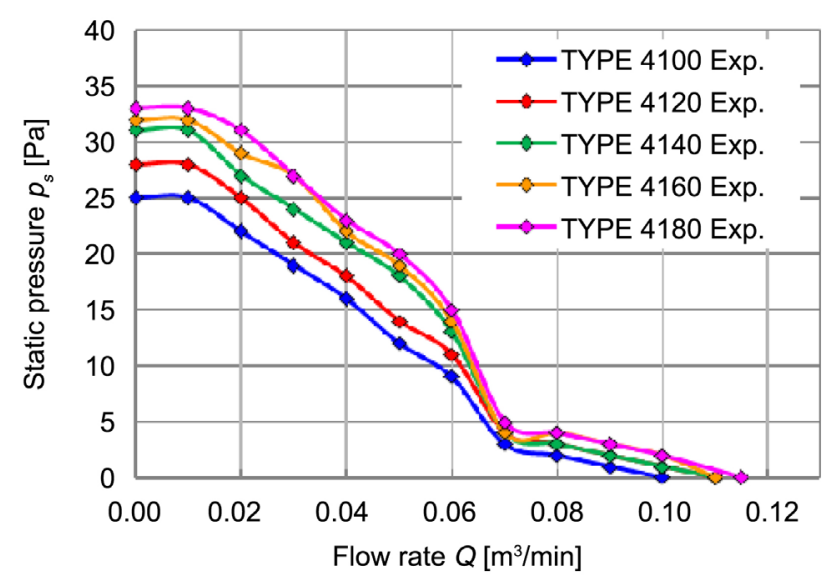

(a)

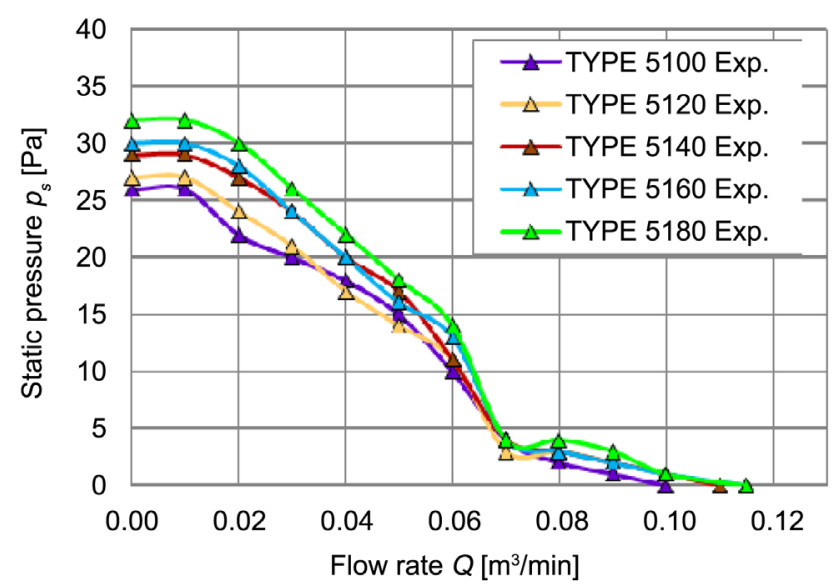

(b)

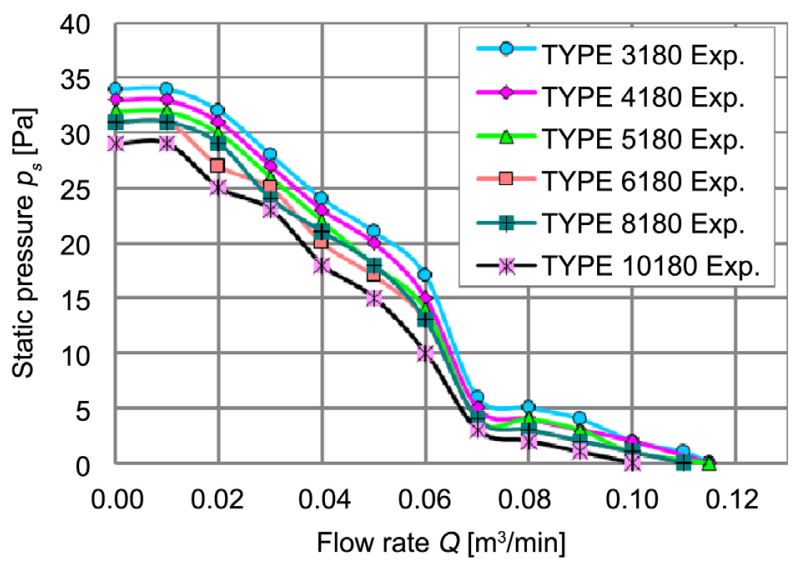

(c)

Figure 6. Comparison of PQ curves. (a) Difference of chord length $L$ (Blade thickness $t=0.4 \mathrm{~mm}$ ); (b) Difference in chord length $L$ (Blade thickness $t=0.5 \mathrm{~mm}$ ); Difference in blade thickness $t$ (Tip chord length $L=19.5 \mathrm{~mm}$ ). 
axis shows the flow rate. In Figure 6(a), the static pressure increased in almost all flow rates as the increase of the chord length and the maximum flow rate similarly increased. TYPE 4180 shows the superior performance characteristics compared with those of other impellers with blade thickness of $0.4 \mathrm{~mm}$. Similar tendency was also observed in Figure 6(b), and TYPE 5180 shows superior performance characteristics. In Figure 6(c), the static pressure increased in almost all flow rates as the decrease of the blade thickness, and the maximum flow rate similarly increased. TYPE 3180 shows superior performance characteristics compared with those of other impellers with different blade thickness.

\subsection{Comparison between Experimental and Analysis Results}

Figure 7 shows the comparison of the experimental and the calculated PQ curves of the difference in chord length and the difference in blade thickness.

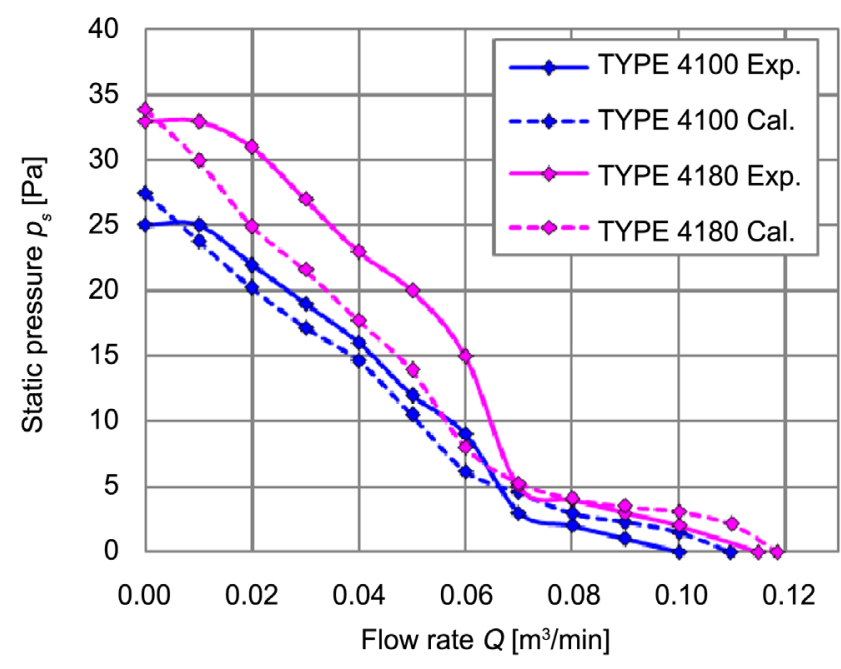

(a)

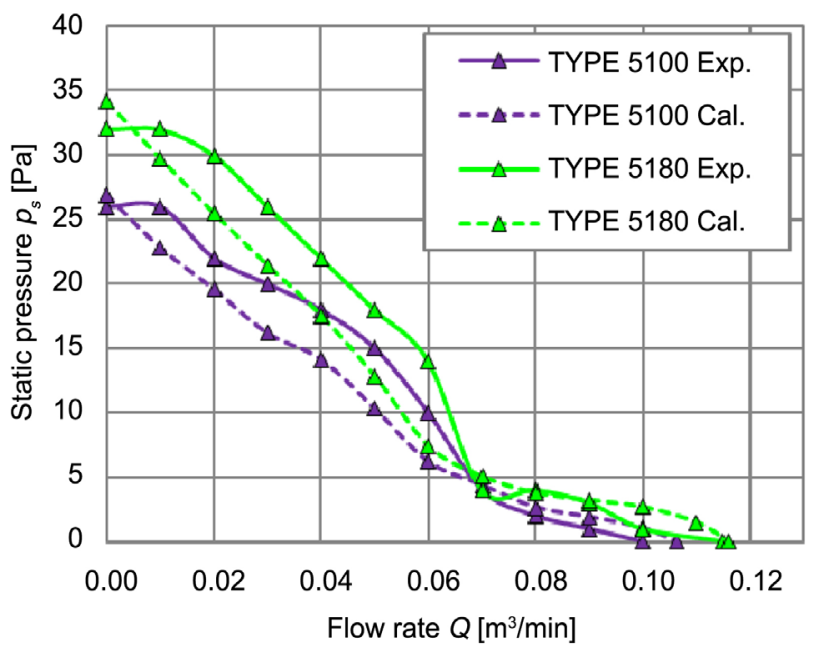

(b)

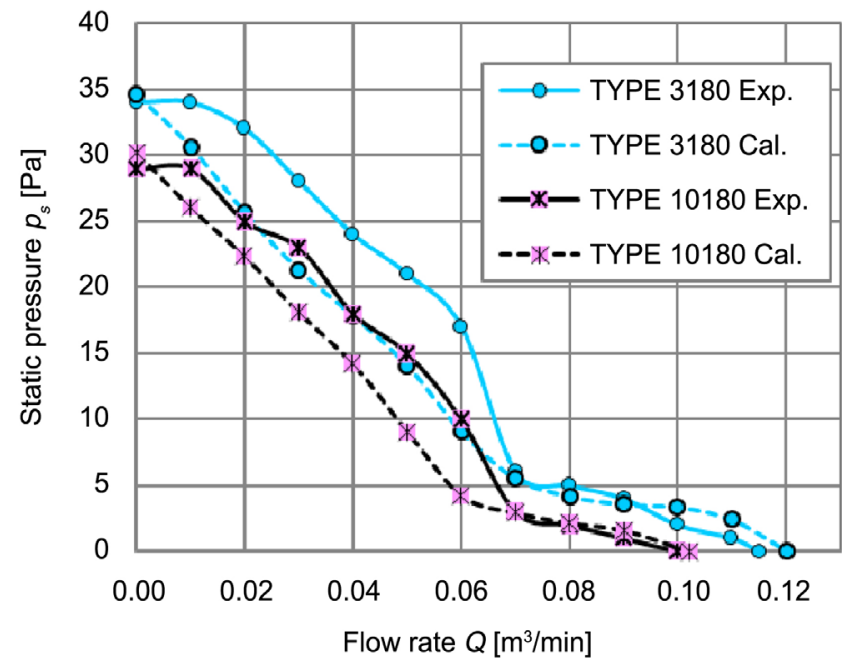

(c)

Figure 7. Comparison of experimental and calculated PQ curves. (a) Difference of chord length $L$ (Blade thickness $t=0.4 \mathrm{~mm}$ ); (b) Difference in chord length $L$ (Blade thickness $t=0.5 \mathrm{~mm}$ ); (c) Difference in blade thickness $t$ (Tip chord length $L=19.5 \mathrm{~mm}$ ). 
Although the static pressure of the analysis result is slightly lower than that of experimental result in less than $Q=0.07 \mathrm{~m}^{3} / \mathrm{min}$, the tendency in more than $Q=$ $0.07 \mathrm{~m}^{3} / \mathrm{min}$ is similar for both the experimental results and the analysis results. It is considered that the analysis could simulate the tendency of the performance characteristics.

\subsection{Blade Efficiency}

Figure 8 shows the comparison of the calculated blade efficiency curves in case that the chord length and the blade thickness were changed. The vertical axis shows the blade efficiency, and the horizontal axis shows the flow rate. The blade efficiency of the tested fan was calculated using the following equation. The torque of the tested fan was the sum of a pressure moment and a viscous force moment on the blade surface.

$$
\eta_{b}=\frac{p_{s} Q}{2 \pi T N}
$$

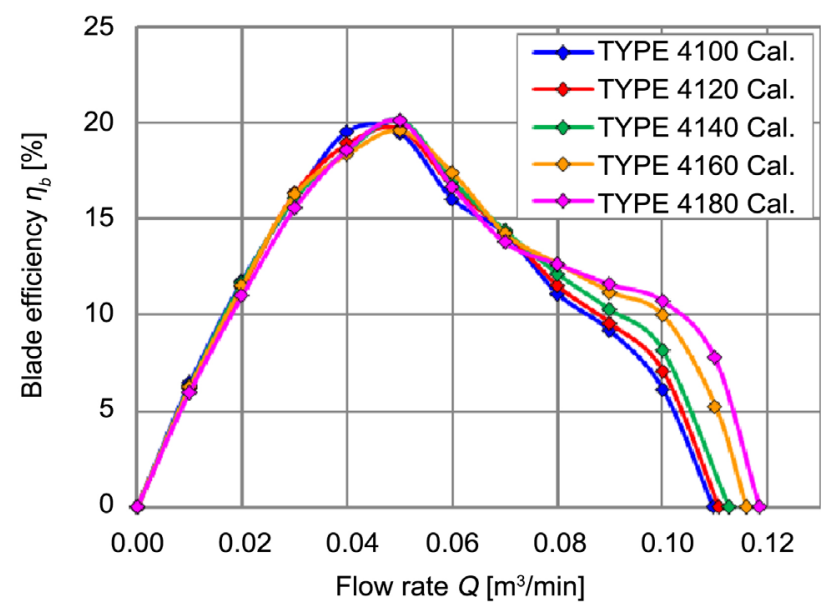

(a)

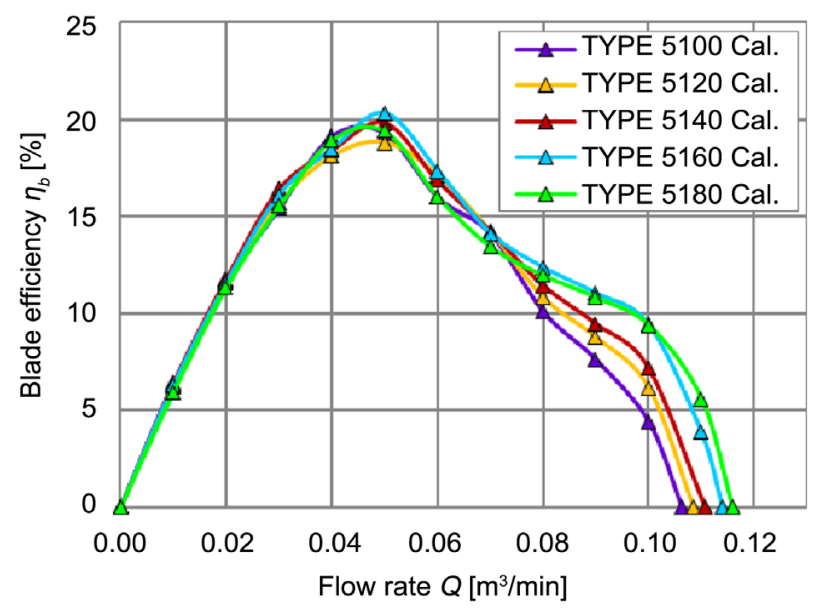

(b)

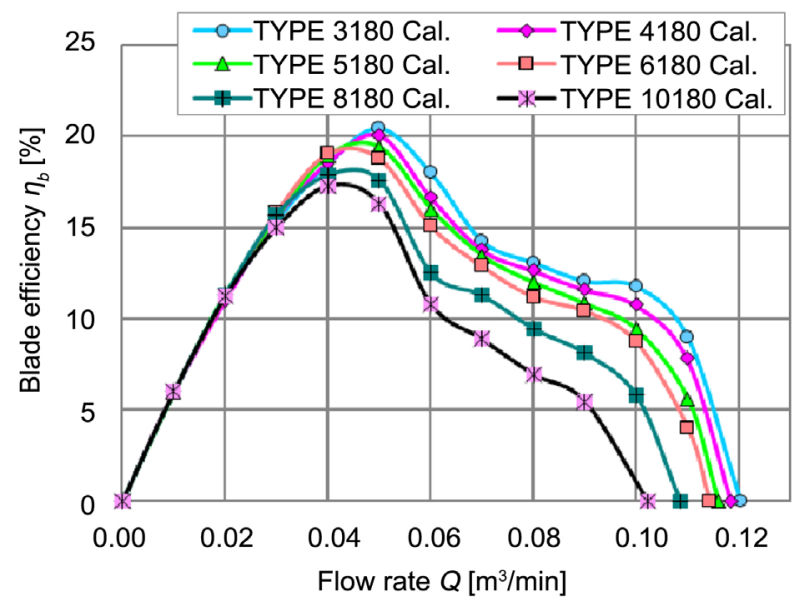

(c)

Figure 8. Blade efficiency curves. (a) Difference of chord length $L$ (Blade thickness $t=0.4 \mathrm{~mm}$ ); (b) Difference in chord length $L$ (Blade thickness $t=0.5 \mathrm{~mm}$ ); (c) Difference in blade thickness $t$ (Tip chord length $L=19.5 \mathrm{~mm}$ ). 
$\eta_{b}$ : Blade efficiency [\%], $T$ : Torque of fan [N.m], $N$ : Rotational speed $\left[\mathrm{min}^{-1}\right]$.

As shown in Figure 8(a), the blade efficiency increased with the increase of the chord length over $Q=0.05 \mathrm{~m}^{3} / \mathrm{min}$. But the maximum efficiency and the maximum flow rate didn't change. Similar tendency was also observed in case of the blade thickness $t=0.5 \mathrm{~mm}$ with different chord length as shown in Figure 8(b). In addition, the blade efficiency increased as the decrease of the blade thickness over $Q=0.05 \mathrm{~m}^{3} / \mathrm{min}$ as shown in Figure $8(\mathrm{c})$. The maximum efficiency of each impeller showed around the $Q=0.05 \mathrm{~m}^{3} / \mathrm{min}$, and the maximum blade efficiency was larger as the blade thickness becomes thinner. Thus, it was found that the increase of the chord length improved the blade efficiency in higher flow rate and the decrease of the blade thickness improved the maximum blade efficiency in higher flow rate.

\subsection{Internal Flow of Fan}

Figure 9 and Figure 10 show the static pressure contour and the velocity vector distribution at the cross section of diameter $d=30 \mathrm{~mm}$ in TYPE 4100, TYPE 4180, TYPE 5100 and TYPE 5180 at the flow rate of $Q=0.10 \mathrm{~m}^{3} / \mathrm{min}$. TYPE 4180 had high static pressure region that was extensively distributed downstream from the fan compared with that for TYPE 4100. The similar tendency also showed in TYPE 5180 as shown in Figure 10. This effect was caused by the increase of the lift of the blade, since the flow along the blade surface did not make flow separation even the chord length was long. Consequently, the static pressure and maximum flow rate were increased. Figure 11 shows the enlarged view of blade leading edge in TYPE 3180 and TYPE 10180 and Figure 12 shows

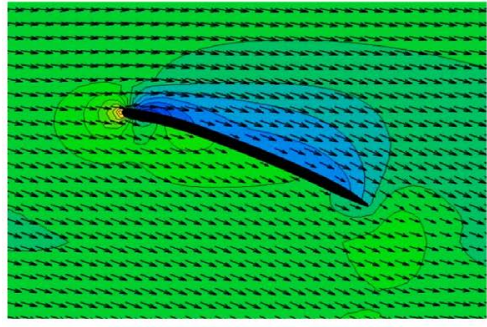

(a)

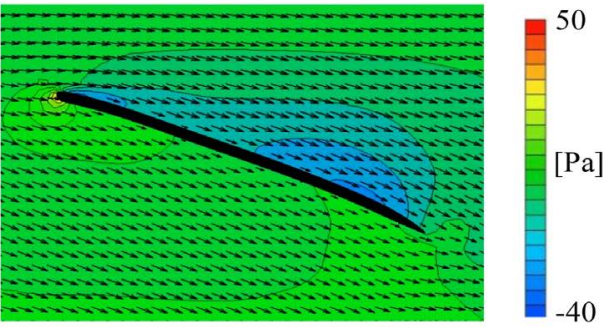

(b)

Figure 9. Static pressure distribution and velocity vector (Blade thickness $t=0.4 \mathrm{~mm}$ ). (a) TYPE 4100. (b) TYPE 4180.

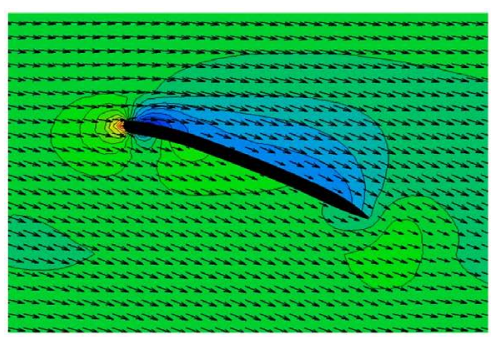

(a)

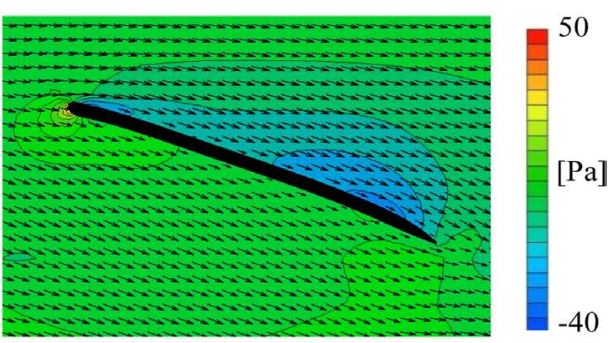

(b)

Figure 10. Static pressure distribution and velocity vector (Blade thickness $t=0.5 \mathrm{~mm}$ ). (a) TYPE 5100. (b) TYPE 5180. 


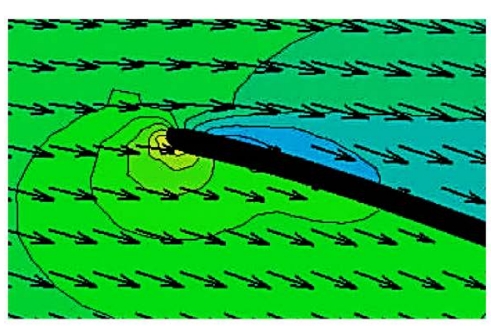

(a)

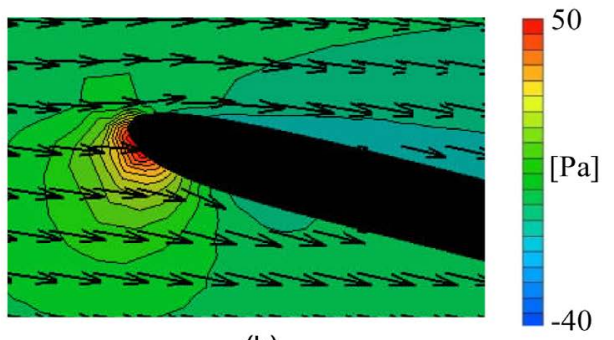

(b)

Figure 11. Static pressure distribution and velocity vector (Tip chord length $L=19.5$ mm). (a) TYPE 3180. (b) TYPE 10180.

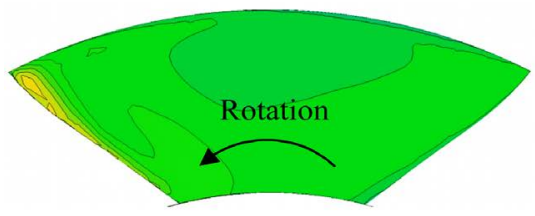

(a)

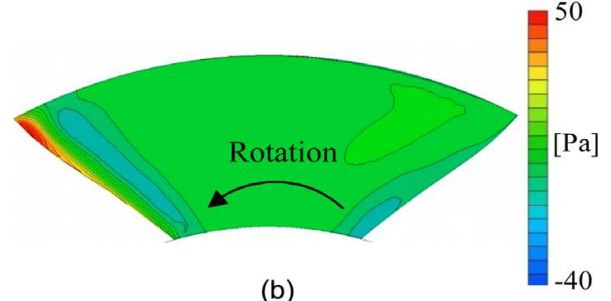

(b)

Figure 12. Static pressure distribution and velocity vector (Tip chord length $L=19.5$ mm). (a) TYPE 3180. (b) TYPE 10180.

the distribution of static pressure on the pressure surface on the same conditions as Figure 9 and Figure 10. The static pressure of TYPE 3180 at leading edge was lower than that of TYPE 10180. It is thought that the incidence loss around the leading edge decreased according to thinner blade thickness. In addition, the pressure on the upper side of TYPE 3180 was more gradually changing than TYPE 10180 and the high static pressure region was expanded. Therefore, the lift of TYPE 3180 was increased and the performance was improved.

\section{Conclusions}

In order to establish the design methodologies of small axial fan for cooling of IT and $\mathrm{AV}$ equipment, various types of impeller were designed and the effects of the dimensions on the performance were investigated by experiment and calculation. The present study obtained the following conclusions.

1) The static pressure increased in almost all flow rate range and the maximum flow rate similarly increased as the increase of the chord length and as the decrease of the blade thickness.

2) Increase of the blade chord led the improvement of the maximum flow rate and the blade efficiency without worsening the internal flow field.

3) The thinner blade thickness made the reduction of incidence loss at the leading edge and the pressure gradient of blade surface was made slowly. As a result, the maximum value of the blade efficiency at higher flow rate was improved as well as the maximum flow rate.

\section{References}

[1] Ito, T., Minorikawa, G., Nagamatsu, A. and Suzuki, S. (2006) Experimental Re- 
search for Performance and Noise of Small Axial Flow Fan (Influence of Parameter of Blade). Transaction of Japan Society Mechanical Engineering B, 72, 670-677. https://doi.org/10.1299/kikaib.72.670

[2] Iwase, T., Hioki, T., Kato, Y., Tanno, T., Sekiguchi, O. and Furukawa, M. (2011) Influence of Interaction with Tangential Lean Blade and Box Type Casing on Blade Passing Frequency Noise Level in Small Axial-Flow Fans. Transaction of Japan Society Mechanical Engineering B, 77, 1620-1629.

[3] Iwase, T., Sugimura K. and Tanno,T. (2009) Study on Improvement of Fan Efficiency in Small Axial-Flow Fans: 1st Report, Designing a High Efficiency Fan by Using Numerical Optimization. Transaction of Japan Society Mechanical Engineering $B, 75,1750-1756$.

[4] Iwase, T., Sugimura, K. and Tanno, T. (2009) Study on Improvement of Fan Efficiency in Small Axial-Flow Fans: 2nd Report, Influence of Tip Leakage Vortex on Static Pressure and Fan Efficiency. Transaction of Japan Society Mechanical Engineering $B, 75,1757-1762$.

[5] Sasajima, T. and Kawaguchi, K. (2011) Numerical Analysis of Flow around Blades in Axial Flow Small Fan. Transaction of Japan Society Mechanical Engineering B, 77, 255-263. https://doi.org/10.1299/kikaib.77.255 